\title{
NECESSIDADE DO FORTALECIMENTO DE POLÍTICAS PÚBLICAS PARA IMPLANTAÇÃO DE ENERGIA RENOVÁVEL: ESTUDO DE CASO FATEC PRESIDENTE PRUDENTE.
}

\author{
Alexandre Godinho Bertoncello ${ }^{1}$
}

\author{
Marcos Medeiros de Souza ${ }^{2}$
}

\author{
Nilmaer Souza da Silva ${ }^{3}$
}

\begin{abstract}
RESUMO
O presente artigo investigou os impactos ambiental e econômico da instalação de painéis fotovoltaicos para geração de energia elétrica em uma instituição pública. A metodologia empregada neste estudo foi de pesquisa exploratória, combinada com uma pesquisa bibliográfica, valendo-se, para tanto, de um estudo de caso de uma unidade educacional da FATEC, na cidade de Presidente Prudente, estado de São Paulo. Os resultados demonstraram haver redução da emissão de dióxido de carbono na atmosfera com a adoção das placas solares, quando comparado à utilização da energia elétrica fornecida pela companhia local, destacando o uso de energia limpa e sustentável no contexto das cidades verdes. Em relação ao impacto econômico, este revelou-se positivo, sendo possível amortizar os investimentos feitos nos ativos de geração de energia solar antes do final da vida útil dos equipamentos. É possível concluir que há viabilidade ambiental e econômica para a instalação do sistema de geração de energia elétrica fotovoltaico, fato relevante no contexto de uma
\end{abstract}

\footnotetext{
${ }^{1}$ Ph.D. Economia Agrícola, Líder do Grupo de pesquisa GDECOR, Professor dos Departamentos de Agronegócio, ADS e Eventos na FATEC, e Departamentos de Administração, Ciências Contábeis e Agronegócio - Unoeste, alexandre.bertoncello@fatec.sp.gov.br

2 Mestre em Educação, Especialista em Finanças, Professor dos Departamentos de Administração e Ciências Contábeis da Universidade do Oeste Pauilista - UNOESTE. msouza@unoeste.br .

${ }^{3}$ Mestre em Bioenergia. Especialista em Administração Financeira. MBA em Finanças Corporativas. Administrador. Professor do Departamento de Engenharia Elétrica e do Departamento de Administração da Universidade do Oeste Paulista - UNOESTE. Nilmaer.silva@fatec.sp.gov.br
} 

Revista Nacional de

Gerenciamento de Cidades

esto resultó ser positivo, es posible amortizar las inversiones en activos de generación de energía solar antes del final de la vida útil de los equipos. Se concluyó que hay viabilidad ambiental y económica para la instalación del sistema de generación de energía fotovoltaica, un hecho material en el contexto de una sociedad sostenible. Cabe señalar que el atractivo financiero de la inversión se puede maximizar mediante la reducción de la carga fiscal de los equipos necesarios para la operación del sistema de generación, lo que confirma el papel de Estado en el desarrollo sostenible de las ciudades y de nuestra sociedad.

PALABRAS CLAVE: Sostenibilidad. Energía Solar. Ciudad Verde.

\section{INTRODUÇÃO}

As questões energéticas sempre foram e serão motivos de ampla discussão entre os diversos flancos da sociedade, dos debates políticos, sociais e, por consequência, das ciências. De um lado figura a necessidade da prosperidade econômica e bem estar humano, e no outro, as questões ambientais. Fato é que, notadamente, esses fenômenos são indissociáveis.

A crescente preocupação com as questões ambientais e a necessidade de se perpetuar a economia sustentável, emerge da necessidade de buscar fontes energéticas menos impactantes ambientalmente e economicamente viáveis. Não se deve dissociar temas como desenvolvimento sócio econômico, matriz energética, consumo, exploração de recursos naturais, mitigação da emissão de poluentes, dentre tantos outros. Surge, assim, a necessidade de uma avaliação conjuntural e sistêmica dos impactos ambientais e financeiros da substituição, ainda que parcial, de combustíveis fósseis e outras fontes mais tradicionais de energia elétrica, tal como a hidroeletricidade, por fontes menos impactante ambientalmente, como por exemplo, a energia eólica e solar.

A característica negativa da exploração da energia elétrica por meio das fontes fósseis e dos demais grandes empreendimentos de geração de energia elétrica passa pela degradação ambiental em todo o seu ciclo de vida, desde a sua extração, passando pelo processo de transformação e, por fim, na operação das usinas e, consequentemente, na combustão dos combustíveis fósseis; além dos eventuais e usuais acidentes no curso de suas operações, ocasionando desastres, 
Revista Nacional de

Gerenciamento de Cidades

passivos ambientais e econômicos, impactando, sobremaneira, toda a sociedade brasileira. Não é diferente no processo de geração das hidrelétricas. Áreas precisam ser inundadas, famílias, por vezes, precisam ser removidas para este processo, além dos custos incorridos em obras destas proporções, ressaltando, sobretudo, o impacto ambiental gerado neste contexto.

Dessa conjuntura, importante colaboração pode dar a geração distribuída, ou seja, a geração de enerigia elétrica nas proximidades do carga, isto é, do consumidor final. Por conseguinte, esta pesquisa tem como delimitação a avaliação do impacto ambiental e econômico da implantação de painéis solares na unidade da Fatec de Presidente Prudente (Fatec PP). A Fatec PP faz parte da autarquia do Governo do Estado de São Paulo vinculada à Secretaria de Desenvolvimento Econômico, Ciência e Tecnologia.

O Centro Paula Souza administra as Escolas Técnicas (Etecs) que somam 218 unidades no Estado e as Faculdades de Tecnologia (Fatecs) que estão presentes em 58 municípios com 64 faculdades estaduais. A Faculdade de Tecnologia de Presidente Prudente localiza-se no extremo oeste do Estado de São Paulo, na fronteira com os Estados do Paraná e do Mato Grosso do Sul. A região de Presidente Prudente é considerada polo regional.

O Instituto Brasileiro de Geografia e Estatística - IBGE estimou para o ano de 2014 uma população de 220.599 habitantes em Presidente Prudente. No segundo semestre de 2012 a FATEC de Presidente Prudente recebeu novas instalações com a construção de um novo prédio, cujas dimensões possibilitam a instalação de painéis fotovoltaicos.

Nossa tese é que a implantação de painéis que gerem energia elétrica de modo viável pode ajudar não apenas na economia do consumo na unidade FATEC $\mathrm{PP}$, objeto desta pesquisa, mas também como projeto piloto para todas as outras unidades do Centro Paula Souza, dando ao governo do Estado e a sociedade, uma possibilidade concreta de mudar o modelo de consumo de energia elétrica existente, que atualmente vem demonstrando sua fragilidade e pontos negativos, 
Revista Nacional de

Gerenciamento de Cidades

quer seja sob a vertente econômica, em função das constantas altas nas tarifas de energia elétrica, quer seja em função do impacto ambiental, gerado pelo consumo de energia elétrica oriunda de grandes empreendimentos de geração e de extensas linhas de transmissão.

\subsection{Objetivos}

O objetivo deste ensaio foi avaliar os impactos ambiental e econômico da conexão ${ }^{4}$ on-grid, de um sistema de geração de energia elétrico fotovoltaico com o sistema de distribuição de enerigia elétrica da concessionária local.

- Os impactos ambientais podem ser calculados pela quantidade de unidades carbonos não emitidas à atmosfera, por consequência da instalação dos painéis fotovoltaicos na unidade da FATEC PP.

- Do ponto de vista da sustentabilidade, além do impacto ambiental e do impacto social mencionados do enredo da geração de energia no Brasil, há também o segundo aspecto a ser analisado: a viabilidade econômica e financeira, ao considerar-se que os recursos monetários são escassos em nossa economia. Torna-se necessária a avaliação financeira dessa proposta de investimento de longo prazo, considerando-a como uma oportunidade a ser explorada.

O processo de identificação, avaliação e implantação de um investimento em infraestrutura é conhecido como orçamento de capital. Trata-se de identificar os ativos necessários, os custos envolvidos em sua aquisição e instalação, bem como os benefícios que devem ser gerados com sua implantação. De forma sucinta, envolve uma decisão a ser tomada sobre a viabilidade de um desembolso inicial (investimento inicial), comparado aos benefícios gerados à posteriori, resumidos nos seus respectivos fluxos de caixa que indicarão se haverá alguma vantagem

\footnotetext{
${ }^{4}$ Sistema de geração de energia elétrica conectado ao sistema de distribuição de energia elétrica da concessionária local, sob condições regulamentares da ANEEL.
} 


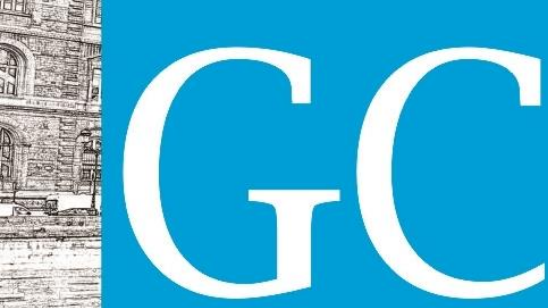

Revista Nacional de

Gerenciamento de Cidades

econômica envolvida na execução do projeto de investimento desenvolvido (Mintzberg, 1994).

Desta forma, foi abordada ao mesmo tempo o viés econômico de viabilidade da implantação do projeto, para esse se estabelecerá três cenários; real, negativo e otimista (Mintzberg 1994) que serão descritos posteriormente e a economia de $\mathrm{CO}_{2}$ gerada pelo empreendimento. Feito isso, será possível verificar, do ponto de vista econômico e da politica social o que os investimentos na unidade da FATEC Presidente Prudente proporcionarão de benéces com a instalação dos painéis solares.

\section{ARGUMENTOS, MÉTODOS E RESULTADOS}

Todo processo produtivo do homem está associado a algum aspecto ambiental, que segundo a ABNT ISO 14001 (1996) pode ser definido como "elemento das atividades, produtos e serviços de uma organização que podem interagir com o meio ambiente" e impacto ambiental como "qualquer modificação do meio ambiente, adversa ou benéfica, que resulte, no todo ou em parte, das atividades, produtos ou serviços de uma organização".

Valle (2011) considera o impacto ambiental como qualquer alteração das propriedades físicas, químicas e biológicas do meio ambiente, causada por alguma forma de matéria ou energia e resultante das atividades humanas que direta ou indiretamente afetam a segurança, a saúde, o bem-estar, as atividades socioeconômicas, a biota, as condições estéticas e sanitárias e a qualidade dos recursos ambientais. Assim, todo o consumo de energia elétrica gera, necessariamente, algum impacto ambiental.

Agregado a isso, nos anos de 2013, 2014 e, agora, em 2015, as condições hidrológicas têm sido desfavoráveis. Isso torna-se evidente nos dados da matriz energética brasileira, a que pode ser entendida como toda energia produzida para ser transformada, distribuída e consumida nos processos produtivos, de uma região, 
Revista Nacional de

Gerenciamento de Cidades

de uma nação ou de um determinado ponto de consumo (VICHI; MANSOR, 2009). A produção e o consumo energético brasileiro são demonstrados no Balanço Energético Nacional (BEN), publicação anual da Empresa de Pesquisa Energética (EPE). A síntese do BEN, de 2015, ano base 2014, deu conta de que a produção de energia elétrica das hidrelétricas foi de $70,6 \%$, contra $76,9 \%$ do ano anterior, enquanto a geração de energia elétrica dos derivados do petróleo saltou de $3,3 \%$ de 2013 para 4,4\% em 2014, além do gás natural, que saltou de $7,9 \%$ para $11,3 \%$, demonstrando, claramente, a dependência da matriz energética brasileira em relação às fontes fósseis.

Assim, considerando a necessidade de se buscar fontes de energia elétrica que deem segurança energética (garantias de suprimento), a Agência Nacional de Energia Elétrica - ANEEL, por meio da Resolução no 482, de 17 de abril de 2012, estabeleceu as condições gerais para o acesso de microgeração e minigeração distribuída, que pode ser entendida como a geração próxima a carga, dispensando o processo de transmissão e distribuição (ACKERMANN; ANDERSON; SODER, 2001), evitando, com isso, impactos ambientais de maior proporção e minimizando, ainda, os custos de implantação, manutenção e operação dos sistemas elétricos.

Nesse enredo, a microgeração distribuída por ser compreendida como uma central geradora, com potência menor ou igual a $100 \mathrm{~kW}$, que utilize fontes renováveis de energia elétrica, como a solar e que estejam conectadas à rede de distribuição da concessionária, por meio das instalações da unidade consumidora, diferindo a minigeração, por esta ter potência maior que $100 \mathrm{~kW}$, mas menor ou igual a $1 \mathrm{MW}$ (ANEEL, 2012).

\subsection{Metodologia e Limitações da Pesquisa}

A metodologia utilizada nesta pesquisa foi de caráter exploratório, a qual proporciona certa familiaridade com a problemática proposta, gerando, com isso, cenários que possam delinear ulterior investigação (SELLTIZ et al, 1987). 
Revista Nacional de

Gerenciamento de Cidades

Para compor um quadro teórico sobre o tema proposto recorremos à pesquisa bibliográfica para buscar referências que suportassem nossos argumentos em prol do uso de energia limpa em organizações estabelecidas no meio urbano. Por derradeiro, esta pesquisa valeu-se de um estudo de caso, para melhor delineamento e limitações do objeto de estudo (CASTRO, 1978).

O prisma utilizado para esta avaliação está na possibilidade de um Estado, com visão estratégica de médio e longo prazo, assim como o Centro Paula Souza ou mesmo outras unidades de ensino do Estado, utilizarem este estudo como plataforma para replicar esta experiência, tal como a FATEC PP para outras unidades, levando em consideração algumas premissas como; a posição geográfica que pode influenciar a capacidade geradora, a relação de metros quadrados disponíveis e a quantidade de alunos por unidade.

A unidade de Presidente Prudente dispõe de $1500 \mathrm{~m}^{2}$ de teto para a instalação de placas solares, mas faz-se necessário, neste caso, apenas uma área de 734 a $899 \mathrm{~m}^{2}$ dependendo dos modelos de equipamentos a serem utilizados. Em qualquer das alternativas, as áreas são livres de problemas de inclinação e sombreamento seja de outras construções ou mesmo de vegetação natural, e a quantidade de alunos na unidade atualmente é de 1113 alunos sendo 60 deles no modulo EAD, ou seja, vão à unidade de forma esporádica.

Desta forma, para os cálculos obtidos, devem ser considerados 1053 alunos presenciais, 60 que cursam Educação a Distância (EAD), 26 funcionários e 64 professores, totalizando 1203 pessoas que compõem a demanda de energia para o funcionamento da unidade. Tem-se, portanto, uma relação de $0.75 \mathrm{~m}^{2}$ de painéis por usuário interno se considerado o orçamento que utilizaria mais metros quadrados ou uma correlação de $0.61 \mathrm{~m}^{2}$ por pessoa com o orçamento que utilizaria menos espaço físico. 


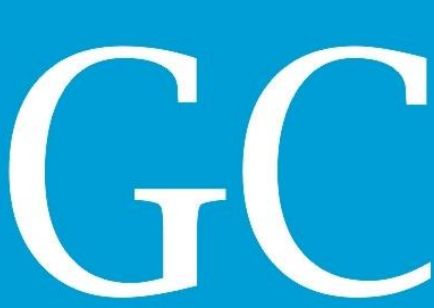

C

Revista Nacional de

Gerenciamento de Cidades

Tabela 1 - Dados técnicos do sistema fotovoltaico e consumo elétrico anual

\begin{tabular}{|c|c|c|}
\hline $\begin{array}{l}\text { Capacidade do sistema: } \\
\text { 109,4 kWp } \\
\text { Inclinação dos módulos: } \\
23^{\circ}\end{array}$ & $\begin{array}{l}\text { Área ocupada: } \\
\text { Orçamento 1: } 734 \mathrm{~m}^{2} \\
\text { Relação usuário por } \mathrm{m}^{2} 0.61 \\
\mathrm{R} \$ 1.105 .800,00\end{array}$ & $\begin{array}{l}\text { Consumo Total: } \\
173064 \text { kWp } \\
\text { - Consumo da rede elétrica: } \\
28120 \mathrm{kWp}\end{array}$ \\
\hline $\begin{array}{l}\text { Radiação sobre os módulos: } \\
\text { 1.756.287 kWp } \\
\text { Emissões de } \mathrm{CO}_{2} \text { evitadas: } \\
55.000 \mathrm{~kg} / \text { ano }\end{array}$ & $\begin{array}{l}\text { Orçamento 2: } 850 \mathrm{~m}^{2} \\
\text { Relação usuário por } \mathrm{m}^{2} 0.71 \\
\mathrm{R} \$ 1.098 .500,00 \\
\text { Orçamento 3: } 899 \mathrm{~m}^{2} \\
\text { Relação usuário por } \mathrm{m}^{2} 0.75 \\
\mathrm{R} \$ 989.900,00\end{array}$ & $\begin{array}{l}\text { - Geração fotovoltaica: } \\
151682 \text { kWp }\end{array}$ \\
\hline
\end{tabular}

Fonte: Inclinação e radiação do simulador do Instituo Ideal (disponível em www.americadosol.org/simulador-solar), redução de $\mathrm{CO}_{2}$ baseado no Quadro 1, Orçamentos feitos com empresas com representantes no Brasil e relação de alunos da unidade local da Fatec Presidente Prudente

Foram utilizados 3 orçamentos de capital para análise e avaliação do projeto de investimentos de longo prazo, que envolveram a determinação de diversos fatores, como dados técnicos, os fluxos relevantes de investimento e duração dos benefícios gerados, a tecnologia existente a ser utilizada, para a avaliação e abrangência do referido projeto. Ao se determinar uma base de premissas realistas pode-se realizar uma projeção de resultados financeiros mais precisa e confiável.

\subsection{Resultados Econômicos}

Os valores da Tabela 1 foram obtidos com base nos dados do simulador solar do Instituto Ideal (www.americadosol.org/simulador-solar). Ressalta-se que os dados são preliminares e não devem ser considerados isoladamente para tomada de decisão final, pois trata-se de um ensaio exploratório. Cada unidade da Fatec deve buscar junto a sua concessionária de energia, ou em empresa devidamente habilitada, os dados de sua realidade local.

O simulador solar está programado para simular geradores de até $1000 \mathrm{kWp}$ $(1 \mathrm{MWp})$ visto que é o limite estabelecido pela resolução normativa $n^{\circ}=482 / 2012$ da ANEEL para consumidores do grupo $\mathrm{B}$ (baixa tensão) e possam ser conectados à rede de distribuição e participar do regime de compensação de energia. 


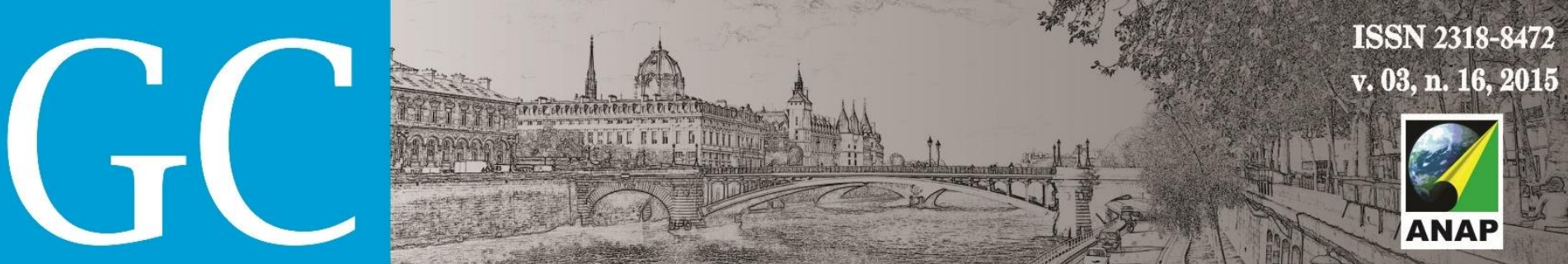

Revista Nacional de

Gerenciamento de Cidades

Tabela 2 - Benefícios gerados com o novo sistema, expressos em kWh

(com base nos dados de consumo de 2014)

\begin{tabular}{|c|c|c|c|c|c|c|}
\hline Mês & $\begin{array}{c}\text { Eletricidade } \\
\text { Consumida } \\
\text { na Fatec (a) }\end{array}$ & $\begin{array}{c}\text { Eletricidade } \\
\text { fotovoltaica } \\
\text { gerada (b) }\end{array}$ & $\begin{array}{c}\text { Eletricidade a } \\
\text { ser fornecida } \\
\text { pela rede (c) }\end{array}$ & $\begin{array}{c}\text { Créditos } \\
\text { gerados } \\
\mathbf{a}-\mathbf{b}(\mathbf{d})\end{array}$ & $\begin{array}{c}\text { Nova eletric. } \\
\text { consumida } \\
\text { prevista (e) }\end{array}$ & $\begin{array}{c}\text { Economia } \\
\text { Gerada } \\
\mathbf{a}-\mathbf{e ~ ( f )}\end{array}$ \\
\hline Janeiro & 13731 & 12985 & 746 & 0 & 746 & 12985 \\
\hline Fevereiro & 20759 & 12015 & 8744 & 0 & 8744 & 12015 \\
\hline Março & 17134 & 13920 & 3214 & 0 & 3214 & 13920 \\
\hline Abril & 16021 & 12673 & 3348 & 0 & 3348 & 12673 \\
\hline Maio & 11439 & 11359 & 80 & 0 & 80 & 11359 \\
\hline Junho & 8164 & 11078 & 0 & 2914 & 0 & 8164 \\
\hline Julho & 9433 & 11403 & 0 & 1970 & 0 & 9433 \\
\hline Agosto & 12238 & 13319 & 0 & 1081 & 0 & 12238 \\
\hline Setembro & 14902 & 13148 & 1754 & 0 & 0 & 14902 \\
\hline Outubro & 19328 & 14031 & 5207 & 0 & 5207 & 14031 \\
\hline Novembro & 17592 & $\mathbf{1 2 5 6 6}$ & 5026 & 0 & 5026 & 12566 \\
\hline Dezembro & 12413 & $\mathbf{1 3 1 8 5}$ & 0 & 772 & 100 & 12313 \\
\hline Total & $\mathbf{1 7 3 0 6 4}$ & $\mathbf{1 5 1 6 8 2}$ & $\mathbf{2 8 1 2 0}$ & $\mathbf{6 7 3 7}$ & $\mathbf{2 6 4 6 5}$ & $\mathbf{1 4 6 5 9 9}$ \\
\hline
\end{tabular}

Fonte: (1) os dados da coluna (a) foram fornecidos pela Fatec Presidente Prudente. (2) os dados das colunas (b), (c) e (d) foram obtidos no simulador solar do Instituto Ideal de acordo com os dados fornecidos para simulação ID: 61048, (disponível em www.americadosol.org/simulador-solar). (3) os créditos gerados, mostrados na coluna (d), aparecem quando o sistema gerar mais energia do que 0 consumo e está prevista na resolução Aneel 482/2012, e somente podem ser aproveitados por um período de 36 meses.

Feitas as análises, é possível inferir que haverá uma grande redução no consumo de energia proveniente da distribuidora local, gerando créditos nos meses em que haveria excedente de produção em relação ao consumo verificado. Logo, a economia gerada totaliza $146.599 \mathrm{kWh}$.

Os fluxos de caixa relevantes são o valor do investimento a ser realizado e os benefícios gerados por tal por tal projeto, que podem ser visualizados na Tabela 3 , e devem ser analisados mediante uma técnica adequada. E a abordagem adequada integra o conceito de valor do dinheiro através do tempo, onde busca-se descontar o fluxo de caixa de acordo com o custo de oportunidade vigente. Trata-se 


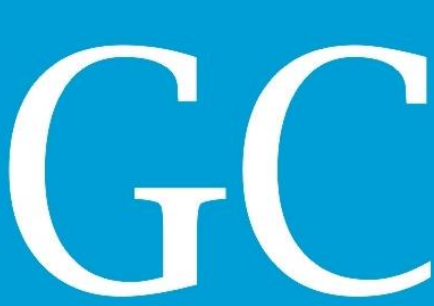

C

Revista Nacional de

Gerenciamento de Cidades

de considerar o custo de capital de longo prazo e os riscos envolvidos. Assim sendo, devemos passar a identificar as variáveis-chaves e as premissas envolvidas, bem como as técnicas de análise a serem utilizadas.

Tabela 3 - Orçamento de Capital (resumo dos dados financeiros)

\begin{tabular}{|l|c|c|c|}
\hline \multicolumn{1}{|c|}{ Critério } & Pessimista & Realista & Otimista \\
\hline Valor do investimento $(\mathrm{R} \$)$ & $\mathrm{R} \$ 1.105 .800,00$ & $\mathrm{R} \$ 1.105 .800,00$ & $\mathrm{R} \$ 989.691,00$ \\
\hline Economia anual gerada $(\mathrm{kWh})$ & 146.599 & 146.599 & 146.599 \\
\hline Valor do $\mathrm{kWh}(\mathrm{R} \$)$ & $\mathrm{R} \$ 0,46$ & $\mathrm{R} \$ 0,55$ & $\mathrm{R} \$ 0,55$ \\
\hline Benefício anual $(\mathrm{R} \$)(1)$ & $\mathrm{R} \$ 67.435,54$ & $\mathrm{R} \$ 80.629,45$ & $\mathrm{R} \$ 80.629,45$ \\
\hline TJLP (\%) & $6 \%$ & $6 \%$ & $6 \%$ \\
\hline Período de tempo & 30 anos & 30 anos & 30 anos \\
\hline
\end{tabular}

Fonte: elaborado pelos autores. (1) $O$ benefício anual é obtido através da seguinte equação: [benefício anual $=$ economia anual gerada $\mathrm{x}$ valor do $\mathrm{kWh}$ ].

A Tabela 3 mostra o benefício financeiro anual, medido em valor monetário, a ser obtido com a utilização da geração de energia elétrica fotovoltaica. Em termos anuais, o montante da redução do custo operacional utilizado para pagamento da conta de energia alcançaria $R \$ 67.435,54$ e $R \$ 80.629,45$ em março de 2015 , nos respectivos cenários apresentados. Para avaliação da viabilidade econômica e financeira do investimento em geração de energia fotovoltaica é pertinente a adoção de três técnicas distintas, mas complementares, quais sejam:

(1) Inicialmente, a técnica do payback é utilizada para estimar o tempo necessário para que a empresa obtenha o retorno do valor desembolsado. De acordo com Gitman (2010, p. 366 ), "O período de payback é o tempo necessário para que a empresa recupere o investimento inicial em um projeto, calculado a partir das entradas de caixa". Essa técnica compara o benefício financeiro obtido com a economia da conta de energia com o valor do investimento (quadro 2), mostrando o período de tempo necessário para equilibrar (ou recuperar) o valor investido inicialmente. Trata-se de uma técnica pouco sofisticada 

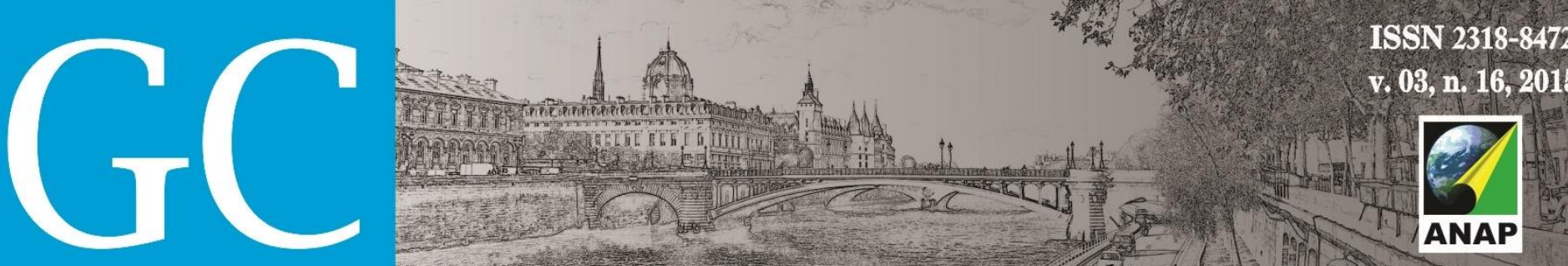

Revista Nacional de

Gerenciamento de Cidades

por não considerar o custo de capital e o valor do dinheiro ao longo do tempo, mas de fácil entendimento.

(2) A técnica do valor presente líquido, que demonstra o valor a ser incrementado como benefício à Fatec PP, após a quitação do investimento, e descontado ao custo de capital evidenciado na TJLP, praticada pelo BNDES - Banco Nacional de Desenvolvimento Econômico e Social (ver Tabela 3). O autor (Gitman, p. 368) diz que "Essa taxa comumente chamada de taxa de desconto, retorno requerido, custo de capital ou custo de oportunidade - consiste no retorno mínimo que um projeto precisa proporcionar para manter inalterado o valor de mercado da empresa".

(3) E, por último, a técnica da taxa interna de retorno que evidencia a taxa percentual de retorno obtida com os benefícios gerados em comparação com o valor investido. Nas palavras do autor (Gitman, p. 370), "É a taxa de retorno anual composta que a empresa obterá, se investir no projeto e receber as entradas de caixa previstas".

A Tabela 4 mostra os valores obtidos com a utilização das técnicas para análise do orçamento de capital, em três cenários distintos. Cabe destacar que para as técnicas do VPL e da TIR foi considerado um período de tempo de 30 anos. Este é o tempo de vida útil das placas fotovoltaicas e do sistema como um todo. Portanto, busca-se propor a vida útil do equipamento como sendo o período de tempo de geração dos benefícios a serem considerados.

Utilizando o orçamento 1, apresentado na Tabela 1, ou seja, aquele que proporcionou a melhor relação de área utilizada e número de usuários $-0.61 \mathrm{~m}^{2}$ desenhamos 3 possíveis cenários (apoiados nas premissas da Tabela 2 e Tabela 3):

- $\left(1^{\circ}\right)$ cenário pessimista onde foi considerada o valor presente da energia sem aumento nos anos seguintes;

- $\left(2^{\circ}\right)$ cenário realista que foi projetado um aumento médio do valor do kWh, de $19,57 \%$ no período, e um 

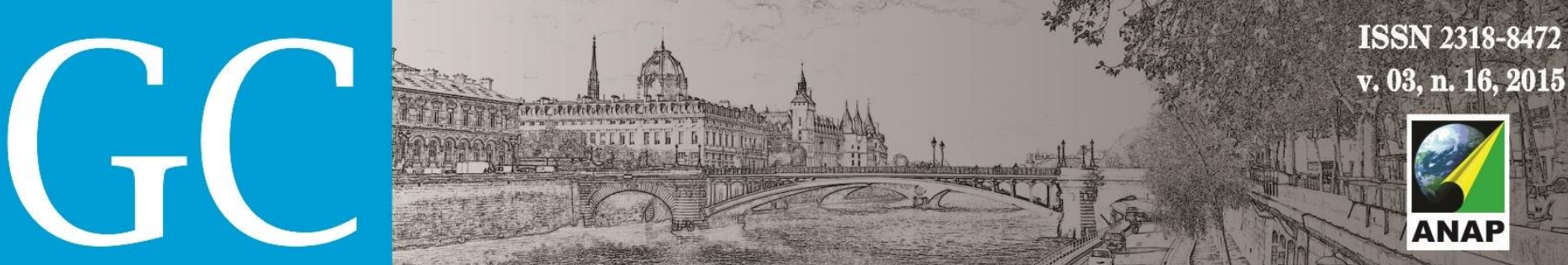

Revista Nacional de

Gerenciamento de Cidades

- $\left(3^{\circ}\right)$ cenário otimista, tem-se, além do aumento médio de $19,57 \%$ ano do valor do kWh, uma sensibilização do Estado e a redução do ICMS para 0\% para implantação de painéis fotovoltaicos em prédios públicos, isso reduziria o orçamento atual em $10.5 \%$.

Tabela 4 - Payback e Valor Presente Líquido

\begin{tabular}{|c|c|c|c|}
\hline Técnica & Pessimista & Realista & Otimista \\
\hline Payback & 16 anos e 5 meses & 13 anos e 9 meses & 12 anos e 4 meses \\
\hline $\mathrm{VPL}-$ Valor Presente Líquido & $-\mathrm{R} \$ 177.561,18$ & $\mathrm{R} \$ 4.050,77$ & $\mathrm{R} \$ 120.159,77$ \\
\hline TIR - Taxa Interna de Retorno & $4,44 \%$ ao ano & $6,03 \%$ ao ano & $7,11 \%$ ao ano \\
\hline
\end{tabular}

Fonte: elaborado pelos autores

Analisando os dados contidos na Tabela 4, podemos perceber que, do ponto de vista econômico e financeiro, há diferenças consideráveis entre os três cenários apresentados. Portanto, é preciso destacar as particularidades de cada um, a partir das premissas utilizadas para orçamento de capital apresentadas na Tabela 3, para que se tenha melhor capacidade de julgamento de tais perspectivas:

- Cenário pessimista - este cenário leva em consideração o valor do kWh de maio de 2015, que é de $\mathrm{R} \$ 0,46 / \mathrm{kWh}$. Neste cenário não é viável a implantação de um sistema fotovoltaico de geração de energia para substituir a eletricidade fornecida pela distribuidora local. O Payback mostra que demoraria 16 anos e 5 meses para que se recupere o valor desembolsado para investimento em tal sistema comparado aos benefícios gerados. É justamente esse tempo longo que acaba por determinar uma baixa taxa de retorno do valor investido que, por sua vez, não cobre o custo de capital evidenciado na TJLP. Ou seja, 4,44\% ao ano de TIR não é suficiente para cobrir os $6 \%$ ao ano da TJLP, causando uma perda de $\mathrm{R} \$ 177.561,18 \mathrm{em}$ termos de VPL, no período de 30 anos.

- Cenário realista - este cenário leva em consideração um aumento real no valor do kWh, levando em consideração o contexto atual do setor 
Revista Nacional de

Gerenciamento de Cidades

energético que necessita realizar vultosos investimentos no aumento da capacidade de geração de energia elétrica. $\mathrm{O}$ valor do $\mathrm{kWh}$ seria de $\mathrm{R} \$ 0,55$, um incremento real de $19,57 \%$ ante a tarifa atual, evidenciado em um aumento real de $1,2 \%$ ao ano por um período de 30 anos e determinado através da média geométrica (BONINI, 1972), que estabelece o valor médio de qualquer progressão geométrica. Com tal valor haveria uma redução do Payback para 13 anos e 9 meses, proporcionando um VPL de $\mathrm{R} \$ 4.050,77$ mostrando geração de valor monetário positiva com taxa de retorno condizente com o custo de capital da TJLP e tornando viável a proposta de investimento.

- Cenário otimista - este cenário leva em consideração o valor ajustado do kWh do cenário realista, e um valor de investimento inicial menor em $10,5 \%$, de $R \$ 989.691,00$, considerando a premissa apresentada de redução do ICMS sobre a comercialização de painéis fotovoltaicos em prédios públicos, reduzindo o orçamento inicial. Isso ampliaria a vantagem econômica, com Payback reduzido de 12 anos e 4 meses e maior geração de valor para a Fatec PP com o VPL alcançando $\mathrm{R} \$ 120.159,77$ e com taxa de retorno prevista de $7,11 \%$ ao ano.

Cabe ressaltar que nos cenários com aumento real de valor do kWh não foi considerada a inflação anual como meio de ajustar os respectivos valores da tarifa de energia elétrica. Isso se deve ao fato de que se buscou trabalhar com valores presentes reais e atuais e com fluxo de caixa descontado pela TJLP. Ou seja, a mesma inflação que seria utilizada para ajustar os preços futuros deveria, também, ser utilizada como taxa de desconto somada ao custo de capital da TJLP, que é uma taxa de juros real e não incorpora a perda do poder aquisitivo da moeda como acontece com a taxa básica e de referência no Brasil (taxa Selic), tornando a inclusão da inflação nos cenários apresentados um "cálculo de soma zero" neste quesito. 

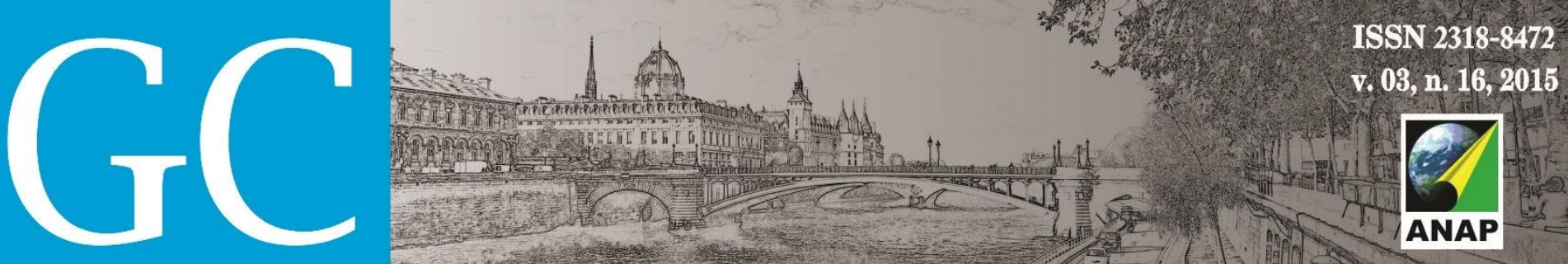

Revista Nacional de

Gerenciamento de Cidades

De forma geral, os resultados mostram que o aumento do valor do kWh se torna um incentivo ao uso de sistemas fotovoltaicos para geração de energia. Esse fato aliviaria a pressão sobre os investimentos na geração de eletricidade do setor como um todo por dois caminhos: (1) diretamente, com maior geração fluxo de caixa das empresas do setor com o aumento da tarifa e (2) indiretamente, ao tornar viável a implantação de sistemas fotovoltaicos para geração de eletricidade, diminuindo a dependência de empresas e organizações públicas do fornecimento das redes de distribuição. Outro fator que se mostra interessante é a redução de preços desses sistemas fotovoltaicos pela menor incidência tributária (ver seção 2.4), que comparado aos benefícios financeiros pode ser amortizado em períodos mais curtos de tempo e proporcionando maior retorno financeiro e uma vantagem econômica.

\subsection{Resultados Ambientais}

Como se vê na Tabela 5, para uma geração de energia elétrica de 151 MWh/ano é possível evitar a emissão de 55 toneladas de dióxido de carbono por ano. Projetando estes dados para 30 anos, que é o tempo de vida útil das placas solares, tem-se 616,5 toneladas evitadas de dióxido de carbono. Vale observar que à medida que se utiliza mais combustíveis fósseis na matriz energética, a exemplo do ocorrido em 2013, 2014 e 2015, este número aumenta, o que garante mais benefícios ambientais com a implantação das placas solares. A respeito da emissão evitada de $\mathrm{CO}_{2}$ ao ano, nota-se:

Tabela 5 - Emissão evitada de $\mathrm{CO}_{2}$

- Fator Médio Anual (tCO $/ \mathrm{MWh}) \mathrm{ANO}-2014=0,1355 \mathrm{tCO}_{2}$ (MIRANDA, 2012; MCT, 2015)

- Energia Elétrica gerada (consumo evitado) $=151,681 \mathrm{MWh}$ (ver tabela 1)

- Conclusão = 0,13552 $\mathrm{tCO}_{2} \times 151,681 \mathrm{MWh}=55$ Toneladas de dióxido de carbono evitada ao ano.

Fonte: elaborado pelos autores. 
Revista Nacional de

Gerenciamento de Cidades

Desta forma, cabe ao Estado em situações análogas buscar a vontade politica de executar empreendimentos como a FATEC Eco Sustentável demonstrando preocupação com o bom uso dos recursos disponíveis e proporcionando a atual e as futuras gerações direitos básicos que proporcionam qualidade de vida como, a água e a energia elétrica.

Neste trabalho ficou claro que a visão do Estado para as fontes de energias fotovoltaicas está longe do ideal, além do chamado custo de disponibilidade que todos aqueles que produzem energia limpa devem pagar, os investimentos neste setor sofrem intensa tributação.

\section{CONSIDERAÇÕES FINAIS}

Sintetizando, a presente pesquisa demonstrou haver a viabilidade ambiental da implantação do sistema de geração de energia elétrica fotovoltaico em detrimento da utilização da energia elétrica proveniente da distribuidora local ao mitigar a emissão de 55 toneladas de dióxido de carbono ao ano e mais de 616 toneladas de dióxido de carbono no período de 30 anos, gerando, com isso, impacto ambiental positivo.

Sob a égide da avaliação econômico-financeira, considerando, sobretudo, a perspectiva dos aumentos vindouros nas tarifas reguladas de energia elétrica, decorrentes da necessidade de investimentos de infraestrutura no setor elétrico, terse-ia um payback de 12 anos e 4 meses, restando, com isso, 17 anos e oito meses de utilização do equipamento após a amortização do investimento, o que caracteriza o projeto como viável economicamente.

A viabilidade ambiental e econômica do uso de energia solar no meio urbano torna a cidade mais verde e proporciona a sustentabilidade de nossa sociedade, algo possível de ser concretizado. 
